\title{
Podcast como potencial recurso didático para prática e a formação docente
}

\author{
Cristiano das Neves Bodart ${ }^{1}$ \\ Zaine Paula dos Santos Silva ${ }^{2}$
}

\begin{abstract}
RESUMO
$\mathrm{O}$ artigo traz três pesquisas que se complementam. Uma marcada por uma análise do estado da arte em torno dos podcasts educativos; uma segunda pesquisa caracterizada por um experimento realizado em uma turma do curso de Pedagogia da Universidade Federal de Alagoas (UFAL) e, por fim, uma avaliação das perspectivas de futuros professores quanto as vantagens e desvantagens de utilização dessa ferramenta tecnológica nas suas aprendizagens, assim como da disposição em utilizar podcasts em suas futuras atuações docentes. A pesquisa evidencia que o volume de teses e dissertações voltadas para o uso de podcasts educativos é ainda reduzido, embora seja numerosa as potencialidades destacadas por esses trabalhos, evidenciando a importância de maiores investimentos no tema e divulgação de práticas bem sucedidas. A partir do experimento notou-se que o podcasts potencializou a aprendizagem dos futuros professores, bem como despertou-os para as possibilidades de seu uso em suas futuras práticas docentes.
\end{abstract}

PALAVRAS-CHAVE: Formação de Professores. Podcast. Recurso Didático.

\section{Podcast as a potential didactic resource for practice and teacher training}

1 Doutor em Sociologia. Universidade Federal de Alagoas (UFAL), Maceió, Alagoas, Brasil. Orcid: https://orcid.org/0000-0002-2195-2145. E-mail: cristianobodart@gmail.com.

2 Graduanda em Pedagogia. Universidade Federal de Alagoas (UFAL), Maceió, Alagoas, Brasil. Orcid: https://orcid.org/0000-0002-9488-2491. E-mail: zaine.paula@hotmail.com. 


\begin{abstract}
The article brings three researches that complement each other. One marked by an analysis of the situation of art around educational podcasts; a second survey characterized by an experiment carried out in a class of the Pedagogy course at the University [...] and, finally, an evaluation of the prospects of future teachers regarding the advantages and advantages of using this technological technique in their learning, as well as willingness to use podcasts in their future teaching actions. Research that proves the volume of theses and dissertations focused on the use of educational podcasts is still small, although it is as large a number as the potentials highlighted by these works, highlights the importance of greater investments in the theme and publication of successful practices. Since the beginning of the experiment, podcasts have enhanced the learning of future teachers, as well as the alarm clocks for the possibilities of use in their future teaching practices.
\end{abstract}

KEYWORDS: Teacher training. Podcast. Didactic Resource.

Podcast como un recurso didáctico potencial para la práctica y la formación del professorado

\title{
RESUMEN
}

$\mathrm{El}$ artículo trae tres investigaciones complementarias. Uno marcado por un análisis del estado del arte en torno a podcasts educativos; una segunda encuesta caracterizada por un experimento realizado en una clase del curso de Pedagogía en la Universidad y, [...] finalmente, una evaluación de las perspectivas de futuros maestros con respecto a las ventajas y ventajas de usar esta técnica tecnológica en su aprendizaje, así como voluntad de usar podcasts en sus futuras acciones de enseñanza. La investigación que muestra el volumen de tesis y disertaciones centradas en el uso de podcasts educativos aún es pequeño, aunque es tan grande como las potencialidades destacadas por estos trabajos, la importancia de mayores inversiones en el tema y la publicación de prácticas exitosas. Desde el comienzo de la experiencia, los podcasts han mejorado el aprendizaje de los futuros maestros, así como los relojes de alarma para las posibilidades de uso en sus futuras prácticas de enseñanza.

PALABRAS CLAVE: Formación docente. Podcast. Recurso didáctico. 


\section{Introdução}

As Novas Tecnologias de Informação e Comunicação (TICs) vem sendo apropriadas por educadores de todas as áreas e níveis de ensino a fim de tornar suas aulas mais dinâmicas, prazerosas e significativas. Durante a quarentena, imposta pela pandemia do Covid-19, no ano de 2020, a busca por recursos tecnológicos se ampliou substancialmente e pesquisas que discutam suas potencialidades e limitações são urgentes.

Num contexto de "vida normal", recursos audiovisuais já são bem presentes e populares nas práticas cotidianas escolares, sobretudo o uso de vídeos e músicas. Contudo, há outros recursos que surgem possibilitados pela Web 2.0 que ainda não ganharam a mesma popularidade, tais como o podcast educacional (podcast-edu). Partindo do pressuposto que a formação de professores pode envolver não só aprendizagem de conteúdos, mas também conhecimento das potencialidades dos usos das TICs na educação, julgamos importante analisar parte da produção científica sobre o tema, bem como explorar as potencialidades do uso desse recurso.

Grosso modo, o podcast consiste em conteúdos de áudio que podem ser acessado a qualquer hora e lugar, permitindo ser armazenado em dispositivos capazes de reproduzir os arquivos. Trata-se de publicações em ficheiros multimídia disponibilizados na internet, o que ficou denominado de Podcasting. Embora o nome podcasting remete diretamente ao iPod, da Apple, pode ser produzido, feito upload, baixado e ouvido por outros equipamentos tecnológicos, principalmente celulares e computadores. Sendo os smartphones uma tecnologia à mão de grande parte dos(as) estudantes, o acesso a tal recurso torna-se facilitado, assim como a possibilidade de produzir e difundir via internet. Como destacou Sampaio-Silva (2019), o som, embora não seja tão atraente quanto as imagens, tem a capacidade de colaborar com o desenvolvimento da capacidade imaginativa dos ouvintes. Os usos de sons 
mais elaborados e planejados, como ocorre nos podcasts, podem despertar o interesse dos(as) estudantes e estimular a concentração.

Neste artigo realizamos, em um primeiro momento, uma pesquisa denominada estado da arte em torno podcast-edu. Por podcast-edu entendemos os podcasts produzidos com objetivo de serem utilizados na educação formal. Após tal mapeamento, discutimos as potencialidades dos usos dessa ferramenta nos diversos níveis de ensino. Num terceiro momento, o foco volta-se para uma prática realizada no ensino superior, no curso de Pedagogia, mais especificamente na disciplina Fundamentos Sociológicos da Educação. Analisa-se a percepção das futuras professoras/pedagogas quanto as potencialidades e limitações dessa ferramenta. Assim, estruturamos nosso esforço em quatro etapas, são elas: i) observação de parte da produção científica sobre podcast-edu; ii) apontamentos das diversas possibilidades didático-pedagógicas de usos desse recurso na educação formal, seja em sala de aula ou no ambiente extra-escolar; iii) relato de experiência docente e; iv) avaliação discente quanto a experimentação da ferramenta, assim como observação de suas percepções de usos de podcasts na prática de ensino-aprendizagem.

O relato da experiência pedagógica e a percepção do corpo discente sobre os usos desse recurso tecnológico na educação se apoiou em duas metodologias: i) pesquisa-ação, ocorrida, , no segundo semestre letivo de 2019, durante a disciplina Fundamentos Sociológicos da Educação, no curso de Pedagogia da Universidade Federal de Alagoas e; ii) questionários, aplicados ao corpo discente que experienciou a produção dos podcasts no contexto da disciplina.

Abordar os usos de podcast como recursos didáticos-pedagógicos importa por, ao menos, contribuir para a sua popularização e problematizar seus usos educacionais, o que corrobora para a qualificação da prática educativa. Assim, este texto corrobora para evidenciar o podcast como ferramenta didática potencializadora do processo de ensinoaprendizagem, seja no ensino básico ou superior, possibilitando auxiliar 
futuros docentes interessados em ampliar seus conhecimentos sobre recursos didáticos e estratégias de ensino. Objetiva-se, também, compreender a percepção de futuros professores quano as potencialidades e limitações do uso de podcasts como recurso pedagógico após experimentar seu uso enquanto discente em formação.

\section{Podcast educacionais: mapeando parte da produção acadêmica}

É certo que há pesquisas sobre o uso de podcast-edu publicadas em diversos locais e formatos. Optamos por priorizar - pelos limites objetivos impostos -, num primeiro momento, a observação da presença dessas pesquisas nos espaços de maior prestígio social (teses, dissertações e artigos indexados no SciELO) e, num segundo momento, em um espaço relativamente conhecido, o Portal de Periódicos, mantido pela Coordenação de Aperfeiçoamento de Pessoal de Nível Superior (Capes). Ainda que os levantamentos realizados não deem conta de todo o campo acadêmico, o que também não é o nosso objetivo, nos possibilita observar o estado da arte e alguns aspectos que envolvem as pesquisas voltadas ao recurso educacional em questão.

Nesse sentido, buscando observar as diversas formas de apropriação de podcast pelos professores, realizamos o levantamento de dissertações e teses disponibilizadas na Biblioteca Digital Brasileira de Teses e Dissertações (BDTD) e no repositório Catálogos de Tese e Dissertações ${ }^{3}$ também mantidos pela Capes. Para tanto, foi usado o descritor "podcast". Feito esse procedimento na BDTD, identificamos 25 resultados, dos quais 12 abordam o podcast-edu. Já no Catálogos de Tese e Dissertações encontramos $54^{4}$ ocorrências, das quais 28 voltam-se para esse recurso pedagógico. Desconsiderando as dissertações e teses que se repetiam nos dois repositórios, restaram 29 trabalhos, como se observa no quadro 1.

\footnotetext{
${ }^{3}$ Disponível em: 〈https://catalogodeteses.capes.gov.br/catalogo-teses/\#!//>. Acesso em: 31 de ago. 2019.

${ }^{4}$ Nesse tipo de busca que realizamos aqui os descritores são buscados no título e no resumo dos trabalhos.
} 
QUADRO 1: Teses e dissertações sobre podcast educacionais presentes na BDTD e no Catálogos de Tese e Dissertações (CNPq), 2019.

\begin{tabular}{|c|c|c|c|c|c|}
\hline Ano & Título & Autor & Programa & Curso & Instituição \\
\hline 2008 & $\begin{array}{l}\text { As possibilidades do } \\
\text { podcast como ferramenta } \\
\text { midiática na educação }\end{array}$ & $\begin{array}{l}\text { FRANCO, } \\
\text { Carolina Machado } \\
\text { dos Santos de } \\
\text { Sousa }\end{array}$ & $\begin{array}{l}\text { Educação, } \\
\text { Arte e } \\
\text { História da } \\
\text { Cultura }\end{array}$ & $\begin{array}{l}\text { Mestrado } \\
\text { acadêmico }\end{array}$ & $\begin{array}{l}\text { Univ. } \\
\text { Mackenzie, } \\
\text { São Paulo }\end{array}$ \\
\hline 2008 & $\begin{array}{l}\text { Podcasting no ambiente } \\
\text { virtual de aprendizagem } \\
\text { moodle: uma pesquisa } \\
\text { exploratória na educação } \\
\text { online }\end{array}$ & $\begin{array}{l}\text { BAHIA, Mayrton } \\
\text { Villa }\end{array}$ & Educação & $\begin{array}{l}\text { Mestrado } \\
\text { acadêmico }\end{array}$ & $\begin{array}{l}\text { Univ. Estácio } \\
\text { de Sá, Rio de } \\
\text { Janeiro }\end{array}$ \\
\hline 2010 & $\begin{array}{l}\text { O gênero podcast } \\
\text { educacional: descrição do } \\
\text { conteúdo temático, estilo } \\
\text { e construção } \\
\text { composicional } \\
\end{array}$ & $\begin{array}{l}\text { UCHÔA, José } \\
\text { Mauro Souza. }\end{array}$ & $\begin{array}{l}\text { Letras- } \\
\text { Linguagem e } \\
\text { Identidade }\end{array}$ & $\begin{array}{l}\text { Mestrado } \\
\text { acadêmico }\end{array}$ & $\begin{array}{l}\text { UFAC, Rio } \\
\text { Branco }\end{array}$ \\
\hline 2010 & $\begin{array}{l}\text { Podcasts educativos: } \\
\text { possibilidades, limitações } \\
\text { e a visão do professor de } \\
\text { ensino superior }\end{array}$ & $\begin{array}{l}\text { PAULA, João } \\
\text { Basílio Costa }\end{array}$ & Educação & $\begin{array}{l}\text { Mestrado } \\
\text { profissional }\end{array}$ & $\begin{array}{l}\text { Ceft-MG, Belo } \\
\text { Horizonte }\end{array}$ \\
\hline 2011 & $\begin{array}{l}\text { Podcasts no ensino de } \\
\text { Alemão como Língua } \\
\text { Estrangeira: um estudo } \\
\text { do impacto de uma nova } \\
\text { tecnologia }\end{array}$ & $\begin{array}{l}\text { CARVALHO } \\
\text { JUNIOR, Paulo } \\
\text { de }\end{array}$ & Letras & $\begin{array}{l}\text { Mestrado } \\
\text { acadêmico }\end{array}$ & $\begin{array}{l}\text { PUC-Rio, Rio } \\
\text { de Janeiro }\end{array}$ \\
\hline 2012 & $\begin{array}{l}\text { A utilização de } \\
\text { ferramentas da } \\
\text { informática educativa } \\
\text { como instrumento } \\
\text { pedagógico no estudo da } \\
\text { eletricidade em uma } \\
\text { perspectiva de } \\
\text { aprendizagem } \\
\text { significativa. }\end{array}$ & $\begin{array}{l}\text { SILVA, Antônio } \\
\text { Mozane Teixeira } \\
\text { da }\end{array}$ & $\begin{array}{l}\text { Ensino de } \\
\text { Ciências e } \\
\text { Matemática }\end{array}$ & $\begin{array}{l}\text { Mestrado } \\
\text { profissional }\end{array}$ & $\begin{array}{l}\text { UFC, } \\
\text { Fortaleza }\end{array}$ \\
\hline 2013 & $\begin{array}{l}\text { Podcast na educação } \\
\text { brasileira: natureza, } \\
\text { potencialidades e } \\
\text { implicações de uma } \\
\text { tecnologia da } \\
\text { comunicação } \\
\end{array}$ & $\begin{array}{l}\text { FREIRE, Eugênio } \\
\text { Paccelli Aguiar }\end{array}$ & Educação & Doutorado & UFRN, Natal \\
\hline 2014 & $\begin{array}{l}\text { Construção SNpleno- } \\
\text { tópicoi + SNproi + verbo no } \\
\text { português do Brasil: uma } \\
\text { análise funcional baseada } \\
\text { no uso }\end{array}$ & $\begin{array}{l}\text { VIEIRA, André } \\
\text { Felipe Cunha }\end{array}$ & Linguística & $\begin{array}{l}\text { Mestrado } \\
\text { acadêmico }\end{array}$ & $\begin{array}{l}\text { UFRJ, Rio de } \\
\text { Janeiro }\end{array}$ \\
\hline 2014 & $\begin{array}{l}\text { Desenvolvimento e } \\
\text { avaliação de podcasts de } \\
\text { divulgação científica } \\
\text { para o ensino médio }\end{array}$ & $\begin{array}{l}\text { MORAES, } \\
\text { Luciane Matos de }\end{array}$ & $\begin{array}{l}\text { Química } \\
\text { Biológica }\end{array}$ & $\begin{array}{l}\text { Mestrado } \\
\text { profissional }\end{array}$ & $\begin{array}{l}\text { UFRJ, Rio de } \\
\text { Janeiro }\end{array}$ \\
\hline 2014 & $\begin{array}{l}\text { Podcast e Educação: um } \\
\text { estudo de caso }\end{array}$ & $\begin{array}{l}\text { JESUS, Wagner } \\
\text { Brito de }\end{array}$ & Educação & Mestrado & $\begin{array}{l}\text { Unesp, Rio } \\
\text { Claro } \\
\end{array}$ \\
\hline 2014 & $\begin{array}{l}\text { Radioblog na Escola: } \\
\text { uma proposta para os } \\
\text { Multiletramentos }\end{array}$ & GRIBL, Heitor & $\begin{array}{l}\text { Linguística } \\
\text { Aplicada }\end{array}$ & Doutorado & $\begin{array}{l}\text { Unicamp, } \\
\text { Campinas }\end{array}$ \\
\hline 2015 & $\begin{array}{l}\text { Contos de ficção } \\
\text { científica como recurso } \\
\text { pedagógico para o ensino } \\
\text { de Física e Astronomia } \\
\end{array}$ & $\begin{array}{l}\text { FERNANDES, } \\
\text { Luis Fernando } \\
\text { Gomes }\end{array}$ & $\begin{array}{l}\text { Ensino de } \\
\text { Física }\end{array}$ & $\begin{array}{l}\text { Mestrado } \\
\text { profissional }\end{array}$ & $\begin{array}{l}\text { UFERSA, } \\
\text { Mossoró }\end{array}$ \\
\hline
\end{tabular}




\begin{tabular}{|c|c|c|c|c|c|}
\hline 2016 & $\begin{array}{l}\text { Cidadania Ecológica: } \\
\text { linguagem midiática e } \\
\text { sustentabilidade } \\
\end{array}$ & $\begin{array}{l}\text { COSTA, Maria } \\
\text { Wilma } \\
\text { Albuquerque } \\
\end{array}$ & Letras & $\begin{array}{l}\text { Mestrado } \\
\text { profissional }\end{array}$ & $\begin{array}{l}\text { UFPB, João } \\
\text { Pessoa }\end{array}$ \\
\hline 2016 & $\begin{array}{l}\text { Espaços públicos, } \\
\text { saberes públicos: um } \\
\text { podcast como espaço de } \\
\text { ensino de História }\end{array}$ & $\begin{array}{l}\text { PEREIRA, Daniel } \\
\text { Carvalho }\end{array}$ & $\begin{array}{l}\text { Ensino de } \\
\text { História }\end{array}$ & $\begin{array}{l}\text { Mestrado } \\
\text { profissional }\end{array}$ & $\begin{array}{l}\text { UFRJ, Rio De } \\
\text { Janeiro }\end{array}$ \\
\hline 2016 & $\begin{array}{l}\text { Metodologias ativas no } \\
\text { ensino de conteúdos } \\
\text { morfofuncionais: uso do } \\
\text { podcast como ferramenta }\end{array}$ & $\begin{array}{l}\text { COUTO, Alexis } \\
\text { Aragão }\end{array}$ & $\begin{array}{l}\text { Ensino em } \\
\text { Ciências da } \\
\text { Saúde e do } \\
\text { Meio } \\
\text { Ambiente } \\
\end{array}$ & $\begin{array}{l}\text { Mestrado } \\
\text { profissional }\end{array}$ & $\begin{array}{l}\text { UniFOA, } \\
\text { Volta } \\
\text { Redonda }\end{array}$ \\
\hline 2016 & $\begin{array}{l}\text { Novos Letramentos no } \\
\text { ensino de Língua } \\
\text { Portuguesa: reflexões } \\
\text { sobre a construção } \\
\text { identitária de alunos de } \\
\text { um nono ano, da } \\
\text { professora e da escola } \\
\end{array}$ & $\begin{array}{l}\text { SILVA, } \\
\text { Claudemira } \\
\text { Maria Rocha }\end{array}$ & Letras & $\begin{array}{l}\text { Mestrado } \\
\text { profissional }\end{array}$ & UFAL, Maceió \\
\hline 2016 & $\begin{array}{l}\text { Podcast: ferramenta } \\
\text { midiática como } \\
\text { instrumento da oralidade e } \\
\text { da promoção da cidadania }\end{array}$ & $\begin{array}{l}\text { ROSA, Vania } \\
\text { Virginia dos } \\
\text { Santos Freire }\end{array}$ & Letras & $\begin{array}{l}\text { Mestrado } \\
\text { profissional }\end{array}$ & $\begin{array}{l}\text { UFBA, } \\
\text { Salvador }\end{array}$ \\
\hline 2016 & $\begin{array}{l}\text { Usos e possibilidades do } \\
\text { podcast no ensino de } \\
\text { História }\end{array}$ & $\begin{array}{l}\text { SOUZA, Raone } \\
\text { Ferreira de }\end{array}$ & $\begin{array}{l}\text { Ensino de } \\
\text { História }\end{array}$ & $\begin{array}{l}\text { Mestrado } \\
\text { profissional }\end{array}$ & $\begin{array}{l}\text { UFRJ, Rio de } \\
\text { Janeiro }\end{array}$ \\
\hline 2017 & $\begin{array}{l}\text { Construção e validação de } \\
\text { podcast com conteúdo } \\
\text { educacional em saúde com } \\
\text { participação ativa de } \\
\text { acadêmicos de } \\
\text { enfermagem }\end{array}$ & $\begin{array}{l}\text { MUNIZ, Ricardo } \\
\text { Alexandre Amaral }\end{array}$ & $\begin{array}{l}\text { Enfermagem } \\
\text { e Educação } \\
\text { em Saúde }\end{array}$ & $\begin{array}{l}\text { Mestrado } \\
\text { acadêmico }\end{array}$ & UFPB, Recife \\
\hline 2017 & $\begin{array}{l}\text { O uso pedagógico do } \\
\text { podcast e formação } \\
\text { inicial do professor: } \\
\text { mudanças de paradigma } \\
\text { educacional }\end{array}$ & $\begin{array}{l}\text { SILVA, Weslley } \\
\text { Kozlik }\end{array}$ & Educação & $\begin{array}{l}\text { Mestrado } \\
\text { acadêmico }\end{array}$ & $\begin{array}{l}\text { Unicentro, } \\
\text { Guarapuava }\end{array}$ \\
\hline 2017 & $\begin{array}{l}\text { Uso pedagógico de } \\
\text { podcast para educação } \\
\text { profissional e tecnológica }\end{array}$ & $\begin{array}{l}\text { SOARES, Aline } \\
\text { Bairros }\end{array}$ & Educação & $\begin{array}{l}\text { Mestrado } \\
\text { profissional }\end{array}$ & $\begin{array}{l}\text { UFSM, Santa } \\
\text { Maria }\end{array}$ \\
\hline 2018 & $\begin{array}{l}\text { O podcast e a leitura } \\
\text { oralizada como recurso } \\
\text { para o envolvimento de } \\
\text { alunos do ensino médio } \\
\text { nas aulas de literatura }\end{array}$ & $\begin{array}{l}\text { VIEIRA, Michele } \\
\text { Lago Machado }\end{array}$ & $\begin{array}{l}\text { Ensino de } \\
\text { Línguas }\end{array}$ & $\begin{array}{l}\text { Mestrado } \\
\text { profissional }\end{array}$ & $\begin{array}{l}\text { UNIPAMPA, } \\
\text { Bagé }\end{array}$ \\
\hline 2018 & $\begin{array}{l}\text { Podcast e a relação } \\
\text { ensino aprendizagem na } \\
\text { odontologia }\end{array}$ & \begin{tabular}{|l|} 
ALMEIDA, \\
Rodrigo \\
Cavalcante de \\
\end{tabular} & Odontologia & $\begin{array}{l}\text { Mestrado } \\
\text { profissional }\end{array}$ & \begin{tabular}{|l|} 
Faculdade \\
Ilapeo, \\
Curitiba \\
\end{tabular} \\
\hline 2018 & $\begin{array}{l}\text { Podcasts no processo de } \\
\text { ensino e aprendizagem da } \\
\text { Língua Portuguesa: o } \\
\text { trabalho com a variação } \\
\text { linguística na era digital } \\
\end{array}$ & $\begin{array}{l}\text { LEITE, Quesia } \\
\text { Dos Santos Souza }\end{array}$ & $\begin{array}{l}\text { Formação de } \\
\text { Professores }\end{array}$ & $\begin{array}{l}\text { Mestrado } \\
\text { profissional }\end{array}$ & $\begin{array}{l}\text { UEPB, } \\
\text { Campina } \\
\text { Grande }\end{array}$ \\
\hline 2018 & $\begin{array}{l}\text { Proposta de repositório } \\
\text { digital para } \\
\text { armazenamento de } \\
\text { podcasts educativos }\end{array}$ & $\begin{array}{l}\text { BOTTON, } \\
\text { Luciane de Ávila }\end{array}$ & Educação & $\begin{array}{l}\text { Mestrado } \\
\text { profissional }\end{array}$ & $\begin{array}{l}\text { UFSM, Santa } \\
\text { Maria }\end{array}$ \\
\hline 2019 & $\begin{array}{l}\text { Intervenção educativa } \\
\text { utilizando um podcast } \\
\text { educacional sobre } \\
\text { hanseníase }\end{array}$ & $\begin{array}{l}\text { FERREIRA, } \\
\text { Mirthis Cordeiro }\end{array}$ & Enfermagem & $\begin{array}{l}\text { Mestrado } \\
\text { acadêmico }\end{array}$ & UFPB, Recife \\
\hline
\end{tabular}




\begin{tabular}{|l|l|l|l|l|l|}
\hline 2019 & $\begin{array}{l}\text { Narrativas digitais em } \\
\text { podcast: dinâmica } \\
\text { avaliativa na disciplina } \\
\text { de História }\end{array}$ & $\begin{array}{l}\text { SILVA, Raphael } \\
\text { de França e }\end{array}$ & $\begin{array}{l}\text { Educação } \\
\text { Matemática e } \\
\text { Tecnológica }\end{array}$ & $\begin{array}{l}\text { Mestrado } \\
\text { profissional }\end{array}$ & UFPB, Recife \\
\hline 2019 & $\begin{array}{l}\text { O uso do podcast como } \\
\text { recurso de aprendizagem } \\
\text { no ensino superior }\end{array}$ & $\begin{array}{l}\text { SILVA, Mauricio } \\
\text { Severo da. }\end{array}$ & Ensino & $\begin{array}{l}\text { Mestrado } \\
\text { acadêmico }\end{array}$ & $\begin{array}{l}\text { Fuvates, } \\
\text { Lajeado }\end{array}$ \\
\hline $\begin{array}{l}\text { Produção e utilização de } \\
\text { podcasts para abordagem } \\
\text { do tema bullying em uma } \\
\text { escola de educação } \\
\text { profissional e tecnológica }\end{array}$ & AKITA, Tieko & Educação & $\begin{array}{l}\text { Mestrado } \\
\text { profissional }\end{array}$ & $\begin{array}{l}\text { IFSP, São } \\
\text { Paulo }\end{array}$ \\
\hline
\end{tabular}

Fonte: BDTD e no Catálogos de Tese e Dissertações (CNPq), 2019.

Dos 29 trabalhos de conclusão de curso de pós-graduação stricto sensu, $62 \%$ (18) foram produzidos por pesquisadores do sexo masculino e $37,9 \%$ (11) do sexo feminino. A partir do levantamento sintetizado e demonstrado por meio do quadro 1 , notamos que a produção acadêmica na pós-graduação stricto sensu que versa sobre o uso de podcast-edu ainda é reduzida, se comparado com recursos mais tradicionais, tais como o uso didático-pedagógico de músicas ou filmes. Usando o mesmo procedimento, como estratégia paramétrica, tomando o descritor "filme", encontramos 2.496 resultados, e para "música" 4.414 ocorrências.

As produções das pesquisas sobre podcasts ocorreram predominantemente nos cursos de mestrado profissional, o que pode estar relacionado ao fato desses cursos voltarem-se à questões mais práticas, cujo "trabalho final do curso deve ser sempre vinculado a problemas reais da área de atuação do profissional-aluno" (CAPES, 2014). Dos 28 trabalhos, apenas dois (2) são teses de doutoramento, sendo um (1) defendido no curso de Educação e outro (1) no curso de Linguística Aplicada. Com exceção das dissertações defendidas no curso de Odontologia (2018) e de Enfermagem (2019), todos os demais trabalhos foram apesentados em programas voltados ao ensino.

Notamos ainda que, nos trabalhos de conclusão de pós-graduação stricto sensu há uma variedade de abordagens em torno do podcast-edu, embora predominando discussões mais gerais do uso dessa ferramenta na educação (7 trabalhos). Encontramos pesquisas voltadas ao uso do 
podcasts no ensino de Língua Portuguesa (5), de Física (2), de História (2), de Língua Estrangeira (1) e de Biologia (1), além de abordagem que envolveram o Ensino a Distância (EaD) (1), projeto de extensão (1), intervenção pedagógica (1), a formação de professores (2) e o ensino superior (4), esses mais especificadamente no cursos de Medicina, Enfermagem, Odontologia e computação. Os dois trabalhos voltados ao uso de podcast-edu na formação de professores focaram na formação inicial e na formação continuada.

Cientes que grande parte da produção de pesquisas são publicizadas por meio de periódicos acadêmicos, buscamos também mapear os artigos disponibilizados no Indexador Scientific Electronic Library Online (SciELO) ${ }^{5}$, adotando os descritores "Podcast" e "Podcasts" e o filtro "Coleção Brasil". Buscando pelo primeiro descritor, encontramos 4 resultados. Na busca, utilizando o segundo descritor, identificamos 3 trabalhos. Desconsiderando os resultados duplicados e os artigos que não tratam do podcast no contexto da educação formal brasileira encontramos dois trabalhos: "Podcast, participação social e desenvolvimento", de Rayane Isadora Lenharo (UNESPAR) e Vera Lúcia Lopes Cristovão (UEL) e; "Potenciais cooperativos do podcast escolar por uma perspectiva freinetiana" (2015), de Eugênio Paccelli Aguiar Freire (UFRN). Utilizando como parâmetro, a busca no indexador SciELO pelos descritores "Filme" e "Música", associado ao filtro "WoS Área Temática: Educação e Pesquisas educacionais”, nos apresentou, respectivamente, 48 e 70 resultados. A quase ausência de artigos publicados em periódicos classificados nos estratos superiores indexados no SciELO tem, muito provavelmente, relação com o fato de ser o podcast uma ferramenta relativamente nova e seu uso na educação ainda recente.

\footnotetext{
${ }^{5} \mathrm{O}$ SciELO é o indexador nacional de maior prestígio social no interior do campo acadêmico. A presença ou a ausência de temas ou objetos de pesquisas nele presentes é um importante indicador de seu status na comunidade científica. Por esse motivo o escolhemos para nossa análise. O indexador está disponível em: 〈https://scielo.org〉.
} 
Realizamos também quatro buscas por artigos no Portal de Periódicos da Capes ${ }^{6}$. Em todas as buscas foram usados três filtros, sendo eles "língua portuguesa", "periódicos revisados por partes" e "artigos". O resultado quantitativo das ocorrências é apresentado no quadro 2 .

QUADRO 2: Ocorrências de artigos em língua portuguesa sobre podcasts educacionais disponíveis no Portal de Periódicos (Jan., 2020).

\begin{tabular}{|c|l|c|}
\hline Busca & \multicolumn{1}{|c|}{ Descritores } & $\mathbf{N}^{\mathbf{0}}$ de ocorrências \\
\hline 1 & "Podcast" e "ensino" & 15 \\
\hline 2 & "Podcast" e "educação" & 15 \\
\hline 3 & "Podcasts" e "ensino" & 18 \\
\hline 4 & "Podcasts" e "educação" & 16 \\
\hline Número de artigos* & $\mathbf{1 3}$ \\
\hline
\end{tabular}

Nota: Foram desconsiderados duplicações e artigos que não são voltados à educação formal brasileira. Fonte: Portal de Periódico Capes, 2020.

Como parâmetro de comparação, buscando, a partir dos mesmos filtros, pelos descritores "música + ensino" encontramos 2.973 resultados. A mesma busca com os descritores "filme + ensino" nos trouxe 1.276 resultados. Esses números nos possibilitam inferir que a presença de artigos sobre podcast-edu disponíveis no Portal de Periódicos Capes é ainda, comparativamente, reduzido.

O quadro 3 apresenta os 13 artigos encontrados no Portal de Periódicos (Jan., 2020).

\footnotetext{
${ }^{6}$ Trata-se de um indexador de menor prestígio social no interior da comunidade científica por vincular revistas com menores exigências de qualidade dos periódicos, contudo, um dos mais conhecidos indexadores brasileiros de periódicos científicos/acadêmicos. Disponível em: 〈http://www.periodicos.capes.gov.br $>$. Acesso em: 31 de ago. 2019.
} 
QUADRO 3: Artigos em língua portuguesa sobre podcasts educacionais disponíveis no Portal de Periódicos (Jan., 2020).

\begin{tabular}{|c|c|c|}
\hline Ano & Título & Autor \\
\hline 2008 & $\begin{array}{l}\text { Podcast, Audacity, Youtube, Skypecast, Chat } \\
\text { e Webquest: possibilidades didáctico- } \\
\text { pedagógicas na Internet para o docente de } \\
\text { língua Inglesa }\end{array}$ & $\begin{array}{l}\text { MARSON, Isabel Cristina V.; SANTOS, } \\
\text { Ademir Valdir dos }\end{array}$ \\
\hline 2010 & $\begin{array}{l}\text { Como os Podcasts podem Auxiliar a } \\
\text { Competência Auditiva no Âmbito Ensino- } \\
\text { Aprendizagem de Espanhol como Segunda } \\
\text { Língua? }\end{array}$ & $\begin{array}{l}\text { FERNANDES, Juliana Da Silva; } \\
\text { ALVES, Maraísa Damiana Soares }\end{array}$ \\
\hline 2014 & $\begin{array}{l}\text { Conceitos tecnológicos voltados a educação: } \\
\text { as novas formas de aprender }\end{array}$ & $\begin{array}{l}\text { LEZME, Jean Roque Santos; } \\
\text { QUAGLIA, Isabela Isabela }\end{array}$ \\
\hline 2014 & $\begin{array}{l}\text { Podcasts para o ensino de Língua Inglesa: } \\
\text { análise e prática de Letramento Digital }\end{array}$ & $\begin{array}{l}\text { REIS, Susana Cristina; GOMES, } \\
\text { Adilson Fernandes }\end{array}$ \\
\hline 2014 & $\begin{array}{l}\text { Relações educacionais do "podcast" brasileiro } \\
\text { com as hierarquias expressivas "online" }\end{array}$ & FREIRE, Eugênio Paccelli Aguiar \\
\hline 2015 & $\begin{array}{l}\text { Gestão de recursos do EaD: como adequar as } \\
\text { tecnologias aos perfis de assimilação }\end{array}$ & $\begin{array}{l}\text { SANCHEZ, Lucia Helena Aponi; } \\
\text { SANCHEZ, Otavio Prospero; } \\
\text { ALBERTIN, Alberto Luiz }\end{array}$ \\
\hline 2015 & $\begin{array}{l}\text { O Censo Demográfico de 2010: telefones } \\
\text { celulares na construção de podcasts } \\
\text { geográficos }\end{array}$ & $\begin{array}{l}\text { FRANCO, Aléxia Pádua; SABINO, } \\
\text { André Luiz; FARIA, Elizabet Rezende } \\
\text { de }\end{array}$ \\
\hline 2016 & $\begin{array}{l}\text { Podcast, participação social e } \\
\text { desenvolvimento }\end{array}$ & $\begin{array}{l}\text { LENHARO, Rayane Isadora; } \\
\text { CRISTOVÃO, Vera Lúcia Lopes }\end{array}$ \\
\hline 2017 & $\begin{array}{l}\text { Ensino de produção oral em língua inglesa } \\
\text { por meio de podcast: relatando uma } \\
\text { experiência com alunos do ensino } \\
\text { fundamental }\end{array}$ & REIS, Susana Cristina dos \\
\hline 2018 & $\begin{array}{l}\text { Planejamento de aulas para contexto } \\
\text { diversos translinguagem, multiletramentos } \\
\text { e os letramentos críticos }\end{array}$ & $\begin{array}{l}\text { OKAIGUSIKU, Alberto Eikiti; } \\
\text { GRANDE, Gabriela Claudino; VILAÇO, } \\
\text { Fabiana Lacerda }\end{array}$ \\
\hline 2018 & $\begin{array}{l}\text { Uso de recursos podcast e webquest no } \\
\text { estudo do tema avaliação na educação } \\
\text { infantil }\end{array}$ & $\begin{array}{l}\text { CARVALHO, Fernanda Beatriz da } \\
\text { Costa Miranda de; LIMA, Cristhiane } \\
\text { Pereira de; DUTRA, Alessandra; } \\
\text { ROSA, Vanderley Flor da; OLIVEIRA, } \\
\text { Jair de }\end{array}$ \\
\hline 2019 & $\begin{array}{l}\text { Audionovelas entre a ficção e a realidade: } \\
\text { narrativas em podcast na disciplina de } \\
\text { História }\end{array}$ & $\begin{array}{l}\text { SILVA, Raphael de França e; ALVES, } \\
\text { Thelma Panerai }\end{array}$ \\
\hline 2019 & $\begin{array}{l}\text { Uso de podcasts como potencializador do } \\
\text { desenvolvimento de gêneros orais em aulas } \\
\text { de língua portuguesa no Ensino Médio }\end{array}$ & $\begin{array}{l}\text { CAMPOS, Valéria Hernandorena } \\
\text { Monteagudo de Campos de; MATUDA, } \\
\text { Fernanda Guinoza }\end{array}$ \\
\hline
\end{tabular}

Fonte: Portal de Periódico Capes, 2020.

Observamos, por meio da quadro 3, que maior parte dos artigos encontrados no Portal de Periódicos (Jan., 2020) estão relacionados diretamente ao uso de podcasts no ensino de língua estrangeira (6 trabalhos). Encontramos 2 trabalhos que discutem os usos dessa 
ferramenta na EaD, 1 no ensino de Geografia, 1 de História, 1 de Língua Portuguesa, 1 na educação infantil e 1 artigo com uma abordagem voltada à educação formal em geral. Ainda que haja abordagem mais especificas às disciplinas, o número de abordagens é reduzido e os usos do podcasts em alguns componentes curriculares não são abordados.

Os 13 artigos envolveram 29 autores, sendo 64,2\% (18) do sexo feminino e $35,7 \%$ (11) do sexo masculino. Apenas uma (1) autora publicou mais de um (1) artigo sobre usos de podcast-edu. Vale ressaltar que esse resultado é praticamente o inverso em relação aos trabalhos de conclusão de pósgraduação stricto senso, aspecto que, em alguma medida, reflete as desigualdades de gênero existente do Brasil.

Nos chamou atenção o fato de apenas dois autores de trabalhos de conclusão de pós-graduação stricto senso ter publicado artigo sobre podcast-edu, sendo eles Eugênio Paccelli Aguiar Freire e Raphael de França e Silva. Eugênio Paccelli Aguiar Freire defendeu sua tese de doutoramento sobre o tema em 2013, em 2014 e 2015 publicou dois (2) artigos, um (1) disponibilizado no SciELO e outro no indexador Periódicos Capes. Já Raphael de França e Silva defendeu sua dissertação de mestrado em 2019, ano que também publicou um (1) artigo sobre podcast-edu disponível no indexador Periódicos Capes. Com isso, podemos inferir que o "podcast-edu" não faz parte da agenda de pesquisa dos pesquisadores que em algum momento esteve pesquisandoos. O fato da maior parte dos pesquisadores ter cursado o mestrado profissional pode, em alguma medida, explicar essa situação, uma vez que muitos que optam por esse tipo de mestrado não buscam, necessariamente, pela carreira de pesquisador.

Dentre os trabalhos encontrados identifica-se muitos maneiras de uso dos podcasts como recursos didáticos-pedagógicos. Ainda que não voltados especialmente à formação de professores, estes nos ajudar a refletir sobre as possíveis adaptações, exercício da seção seguinte. 
Os usos de Podcast como recursos didáticos-pedagógicos na formação e atuação de professores: breve balanço das possibilidades

Duas questões precisam ser clarificadas antes de avançarmos na discussão proposta: i) o uso de podcast na prática docente não pode ser confundido, stricto sensu, como mero entretenimento desassociado do ensinoaprendizagem e; ii) recurso didático-pedagógico não se confunde com estratégias de ensino-aprendizagem.

Etmologicamente, a palavra entretenimento é de origem latina, e vem de enter (entre) e tenere (manter), estando tangenciada da ideia de "manter a atenção ou distrair por meio de uma diversão". Por isso, não adotamos essa palavra por não ser nossa proposta nos limitar a ideia de diversão. Não propomos exatamente entreter o corpo discente, nos termos usados em sala de professores. Inferimos que não se trata de "enrolar" ou "fingir que está dando aula". Defendemos o uso dessa tecnologia como recurso didático-pedagógico potencializador do processo de ensinoaprendizagem e não como mera espetacularização; embora as aulas não precisam ser enfadonhas e adinâmicas.

O relativo barateamento dos equipamentos de informática e a expansão do acesso à internet possibilitou mudanças substantivas nos usos das TICs. Em um primeiro momento houve ampliação do acesso aos discursos midiáticos e, posteriormente, mudanças nas relações produtor/consumidor. A "liberação do polo de emissão" dos discursos (KISCHINHEVSKY, 2006) propiciou aos antes receptores-consumidores a possibilidade de serem também produtores e difusores de mensagens/discursos; embora com repercussões variáveis. Tais mudanças abrem espaço para inovações na apropriação das TICs pelo campo educacional, inclusive o uso de podcasts.

A viabilização da produção de podcasts não é tarefa difícil, pois, como já destacava Primo (2005, p. 17) o mesmo "[...] pode ser produzido 
por uma única pessoa tendo como recurso apenas um microfone ou gravador digital, um computador conectado na internet e algum servidor na rede para armazenamento de seus programas e do recurso RSS". Atualmente é possível produzir bons podcasts usando apenas um smartphone, existindo diversos aplicativos gratuitos para esse fim. Outra vantagem destacada por Primo (2005) quanto ao podcast está no fato do ouvinte poder estocar diversos programas em seu computador, MP3 player ou celular e poder escutar no momento que mais lhe convier e quantas vezes desejar. Essa vantagem possibilita a sua reutilização pelo professor em outros momentos e turmas, assim como serem acumulados e/ou guardados pelos alunos para estudos de revisão de conteúdos ou disponibilizados na internet para acesso livre (SAMPAIOSILVA; BODART, 2015).

Também devemos observar as diferenças existentes entre recurso didático-pedagógico e estratégias didáticas. Enquanto o primeiro refere-se ao "meio", ao material, ao "instrumento" aplicado à atividade educativa; o segundo refere-se a formas de usos educacionais, sendo parte da metodologia de ensino (SILVA, 2020). Dito isto, um recurso (no caso o podcast) pode ser utilizado de diversas maneiras, multiplicando as formas de alcançar os objetivos educacionais desejados. Podcasts quando produzidos pelo professor, por exemplo, terão resultados diversos daqueles alcançados em práticas onde os alunos são produtores. Da mesma forma, suas potencialidades e limitações variam de acordo com suas formas.

O podcast foi utilizado por Sampaio-Silva e Bodart (2018) como estratégia para buscar aproximar os conteúdos de Sociologia da vivência e da linguagem cotidiana dos alunos. Os professores produziram, em formato de áudio, podcasts expositivos que mesclaram a formalidade e a informalidade no intuito de explicar conteúdos integrantes do plano de disciplina. A experiência evidenciou que o uso de podcast-edu pode tornar os conteúdos mais atraentes e, consequentemente, despertar o interesse discente para disciplina. O bom resultado alcançado por Sampaio-Silva e 
Bodart (2018) pode ser explicado, em certa medida, ao fato de terem produzidos os episódios conhecendo os gostos dos alunos e atendendo os objetivos de suas aulas.

Souza (2016) se propôs, a partir de uma oficina de produção de podcast destinadas a professores, discutir as potencialidades do uso do podcast para o ensino de História na educação básica. Destacou que esse recurso pode aproximar os espaços escolares, públicos e acadêmicos, possibilitando ao professor "o protagonismo de efetivar uma verdadeira convergência entre estes espaços" (SOUZA, 2016, p. 82). Mais ainda, o podcast pode estabelecer o diálogo entre o conhecimento ensinado na escola com o ciberespaço (SOUZA, 2016), tornando tais conhecimentos mais acessíveis a outros públicos (BARROS; MENTA, 2007).

Explorando o uso de podcast para o ensino de Geografia, Paixão (2016) identificou, por meio de experimento, que além dessa ferramenta auxiliar na aprendizagem dos conteúdos de Geografia e desenvolver habilidades de uso das TICs, o recurso colaborou para reduzir a timidez dos alunos e aprender a trabalhar de forma colaborativa. Além disso, fez com que habilidades e conhecimentos que os alunos previamente possuíam fossem valorizados, mobilizados e aperfeiçoados, o que é de grande importância na sociedade contemporânea. Destacaram Barros e Menta (2007) e Paixão (2016) que o aprendizado não se limitou aos alunos produtores dos podcasts, se estendendo a outros alunos que tiveram acesso aos mesmos. Para Barros e Menta (2007) professor e aluno, na produção de podcasts, podem participar em conjunto da elaboração de conhecimento, potencializando o ensino-aprendizagem dos envolvidos.

Para Souza (2017) "o podcast se desvincula da ideia de padronização do processo de construção do conhecimento, colocando diferentes formas de se construir o pensamento" (SOUZA, 2017, p. 56-57), dando voz aos alunos, permitindo a visibilidade de suas produções em áudio e possibilitando o compartilhamento das experiências entre alunos e entre os docentes (BARROS; MENTA, 2007). Dar voz aos sujeitos 
historicamente silenciado no processo de ensino-aprendizagem é fundamental para tornar as práticas escolares democráticas. O podcast possibilita explorar o "lugar de fala" dos alunos, dando-lhes condições de expressar suas interpretações do mundo social a partir do lugar que ocupam na sociedade. Como destacou Souza (2017, p. 56), “[...] o podcast pode ser um veículo midiático de problematização de questões sociais e históricas produzidas pelos próprios alunos que perpassam o ambiente escolar, trazendo cidadania e dando voz aos alunos em expressar seus anseios e suas ideias". A produção discente de podcasts os desperta para a construção social do discurso e sua relação com as formas de interpretar o mundo social. No processo de formação de professores, experimentar essas emoções como alunos é importante para que mensurem a importância do uso dessa estratégia nas suas futuras práticas docentes.

Silva (2017), autora do único trabalho de conclusão de cursos de pósgraduação stricto sensu voltado para o uso podcasts na formação de professores, identificou, a partir de seu experimento, que dos 15 professores em formação que participaram do "curso de podcast" ministrado pela autora, 12 afirmaram que pretendem usar essa ferramenta em sua futura prática docente. O contato com essa ferramenta despertou os futuros professores para a importância de se apropriar das TICs.

Loures (2018) buscou discutir as possibilidades, vantagens e desvantagens do uso de podcasts para o ensino de História no Ensino Fundamental. Destacou que a produção desse recurso despertou a criatividade artística dos alunos e ampliou suas participações nas aulas e na produção do conhecimento, sentindo-se mais seguros quanto aos conhecimentos adquiridos e orgulhosos de suas obras. $\mathrm{Na}$ experiência de Loures (2018) também notamos que o podcast pode estimular a produção de conhecimento, tornando o aluno agente nesse processo, despertando seu interesse pela pesquisa. 


\section{A experimentação do uso de Podcast: um relato de experiência na formação de professores}

$\mathrm{Na}$ presente seção apresentamos um experimento realizado, no segundo semestre de 2019, na disciplina de Fundamentos Sociológicos da Educação, em uma turma do curso de Pedagogia da Universidade Federal de Alagoas, composta por cerca de dezoito (18) alunos, todos do sexo feminino e com idade predominante entre 19 a 25 anos. Destacamos que a presente pesquisa obedece aos procedimentos éticos estabelecidos para a pesquisa científica em Ciências Humanas na Resolução n. 510, de 07 de abril de 2016.

Importa destacar que o uso pedagógico de uma tecnologia e suas potencialidades variam de acordo com o perfil dos alunos, do professor, da cultura escolar, do currículo, etc. Isso significa dizer que uma experiência pode ser exitosa em uma realidade e em outra não, assim como as experiências aqui narradas não devem ser tomadas como exemplo replicável sem adaptações necessárias a cada realidade. Importa dizer que o uso arbitrário das mídias em sala de aula não contribuem para a análise e investigação de conteúdos, a arbitrariedade impede o aluno também de se tornar construtor de conhecimento (BARRO; MENTA, 2007)

\section{Experimento numa turma de Pedagogia}

Na disciplina Fundamentos Sociológicos da Educação, ministrada no curso de Pedagogia da Universidade Federal de Alagoas, no segundo semestre de 2019, propusemos usar o podcast como recurso didático-pedagógico. Como estratégia didática optamos por trabalhar com a produção desse recurso sonoro, buscando explorar o potencial educativo existente na produção de podcasts ao invés de e apenas voltar-se a apresentação de episódios/programas produzidos por terceiros.

A experiência de uso de podcast no processo de ensino-aprendizagem junto aos alunos do curso de Pedagogia ocorreu em dois momentos distintos, 
mas no mesmo bimestre. Uma primeira experimentação em que todos produziram o recurso sonoro sobre o mesmo tema e uma segunda experiência, no fim do semestre, em que cada dupla de estudantes produziu podcasts com temas diversos abordados na disciplina.

A primeira experiência se iniciou com a apresentação o corpo discente das características de um podcast. Foi solicitado que buscassem, em casa, escutar alguns episódios disponíveis em aplicativos online. $\mathrm{Na}$ aula seguinte, após uma semana, as estudantes foram organizadas em duplas para produzir seus podcasts, cujo objetivo era abordar as contribuições teóricas de Louis Althusser (1918-1990) aos estudos da Educação. A partir dessa proposta, julgamos ter alcançado o que Primo (2005) indicou ao destacar as potencialidades do podcast: a passagem da interação meramente reativa a interações mútuas entre os alunos/produtores.

Foi entregue as estudantes um modelo de roteiro para a produção do conteúdo de áudio, o qual deveria possuir cerca de 8 minutos. O roteiro indicava elementos de abordagem obrigatória. A produção deu-se fora do horário da aula por demandar tempo e ambiente silencioso. As estudantes deveriam enviar suas produções ao professor por e-mail para ser, na aula seguinte, ouvidas pela turma.

A segunda experiência deu-se no mesmo formato, porém os temas variaram de acordo com os autores estudados ao longo da disciplina e os estudantes se organizaram em grupos de três ou quatro pessoas. O objetivo foi utilizar a atividade como forma de revisar os conteúdos estudados nos dois bimestres antes da avaliação da disciplina, podendo os estudantes compartilhar suas produções.

A partir dessas duas experiências observarmos muitas das potencialidades destacadas pela literatura especializada. Notamos que o uso de TICs corrobora com a aprendizagem, pois todos os grupos apresentaram um podcast com bom conteúdo e tiveram bom desempenho na avaliação escrita. Notamos que, mesmos as estudantes mais tímidas foram capazes de produzir seu programa de áudio, isso porque sua produção pode ocorrer em 
lugares onde sentiam mais segurança ou privacidade, como relatou uma das produtoras. Outro aspecto observado refere-se às condições que o podcast cria para que haja trabalho colaborativo, ainda que a turma fosse marcada por grupos de estudantes que não interagiam nas aulas com outros grupos. Observamos no conteúdo do podcast a presença de criatividade e conhecimentos que as estudantes já possuíam, percebendo que esses eram úteis e estavam sendo valorizados na atividade acadêmica. Destacamos ainda que, a produção discente provocou nas estudantes/produtoras a valorização do resultado de seus trabalhos. Parte da literatura especializada (LOURES, 2018) indica que os podcasts podem estimular nos(as) estudantes o interesse pela produção de conhecimento; contudo, tal potencialidade não conseguimos observar por demandar acompanhamento mais duradouro do desenvolvimento intelectual dos(as) discentes, assim como seria difícil isolar uma variável e testá-la como responsável pelo estímulo. Ter propiciado aos futuros professores a experimentação desse recurso didático possibilitou experienciar as potencialidades e limitações dos usos de podcast-edu.

\section{Percepção discente das potencialidades do podcast como recurso didático-pedagógico}

Os(as) discentes são importantes agentes do processo de ensinoaprendizagem. Assim, buscamos não limitar a avaliação do uso de podcasts como recurso didático-pedagógico a partir apenas de nossa (docente e monitora) experienciação e percepções, mas também compreender como as estudantes avaliam um dos tipos (podcast autoral) e utilização de tal recurso, seja como discentes, ou como futuras professoras.

Assim, concretizado nosso experimento, buscamos identificar a percepção das estudantes quanto aos pontos positivos e negativos do seu uso no ensino. Para obtenção de dados referente a essa percepção, foi 
disponibilizado um questionário online através do google forms ${ }^{7}$ para que as estudantes acessassem de seus celulares e o respondessem.

O questionário foi constituído de nove (9) questões, as quais envolveram o conhecimento prévio existente sobre a mídia apresentada e a experiência de produzir um podcast. Também questionou-se sobre a influência positiva ou negativa da ferramenta na aprendizagem do conteúdo proposto, sobre a possibilidade de uso dessa ferramenta no ensinoaprendizagem de outros conteúdos e em outros níveis de ensino. Ou seja, exploramos a percepção das estudantes em face à formação docente.

A turma na qual o experimento foi desenvolvido era constituída por dezoito (18) estudantes. A solicitação para que respondessem o questionário foi disponibilizada no grupo de WhatsApp da disciplina, no qual quase todos participavam. Dez (10) estudantes aceitaram voluntariamente responder o questionário. As respostas nos forneceram elementos colaborativos para compreendermos a percepção discente do uso de podcast como recurso didático-pedagógico. Dados que passamos a demonstrar e discutir.

Quanto ao conhecimento prévio da mídia podcast, $80 \%$ já tinham ouvido falar. Contudo, apenas $10 \%$ o conheciam como recurso didático. Assim, trabalhar o podcast em sala de aula foi, em grande medida, uma novidade para a turma, o que ampliou o repertório de recurso que futuramente poderão utilizar em suas práticas docente; já que tratavam-se de estudantes do curso de Pedagogia, portanto, professoras em formação.

A experiência de produzir podcast foi avaliada de forma positiva, tendo $60 \%$ das respondentes a avaliada como boa e 40\% como ótima. Dentre os respondentes, $100 \%$ apontaram que produzir podcast potencializou a aprendizagem sobre o assunto tratado em sala de aula. Fato confirmado com a avaliação bimestral aplicada na disciplina, tendo sido os conteúdos abordados nos podcasts os que tiveram melhor aproveitamento; o que dialoga

\footnotetext{
${ }^{7}$ Ferramenta gratuita oferecida pela Google. Disponível em: 〈https://docs.google.com/forms/〉. Acesso em: 31 de set. 2019.
} 
com o que Barros e Menta (2007) ponderaram em relação ao potencial pedagógico da produção de podcast-edu.

Notamos que $100 \%$ das respondentes consideraram o podcast como uma ferramenta a ser utilizada no ensino-aprendizagem de outros conteúdos e níveis de ensino, o que corrobora com o que Silva (2017) identificou após curso ministrado à futuros professores. Além disso, 70\% utilizariam o podcast na sua prática docente e 30\% responderam que talvez usariam. Esses dados revelam que essa ferramenta passou a ser considerada pelos futuros professores como uma possibilidade às suas práticas profissionais, relevandose potencializadora da formação docente.

Sobre as respostas às perguntas abertas, alguns relatos se destacam com relação as possíveis vantagens dos usos de podcasts como recursos didáticos. As vantagens apontadas pelas estudantes são apresentados no quadro 4:

QUADRO 4: Perspectivas das estudantes quanto aos possíveis aspectos positivos do uso de podcasts na Educação.

\begin{tabular}{|l|l|}
\hline \multicolumn{1}{|c|}{$\begin{array}{c}\text { Aspecto } \\
\text { ressaltado }\end{array}$} & \multicolumn{1}{c|}{ Sínteses dos relatos } \\
\hline $\begin{array}{l}\text { Foco no } \\
\text { conteúdo }\end{array}$ & $\begin{array}{l}\text { "Permite dedicar uma maior atenção ao conteúdo, levando a realização de } \\
\text { pesquisas adicionais sobre o assunto"; }\end{array}$ \\
\hline $\begin{array}{l}\text { Aprendizagem } \\
\text { facilitada }\end{array}$ & $\begin{array}{l}\text { "Facilita a assimilação do conteúdo, por ser uma mídia que pode ser } \\
\text { qualidade, também consegue passar suas informações de forma mais } \\
\text { direta e com uma linguagem mais clara, através de bate-papo, } \\
\text { entrevistas e curiosidades, facilitando o entendimento"; }\end{array}$ \\
\hline $\begin{array}{l}\text { Contato com } \\
\text { conteúdo }\end{array}$ & "Leva o aluno à interação direta com o assunto"; \\
\hline $\begin{array}{l}\text { Interatividade } \\
\text { com o conteúdo }\end{array}$ & $\begin{array}{l}\text { "Promove o estudo de determinados conteúdo de forma interativa, através } \\
\text { do uso da tecnologia"; }\end{array}$ \\
\hline $\begin{array}{l}\text { Criatividade e } \\
\text { desinibição }\end{array}$ & $\begin{array}{l}\text { "O processo criativo envolvido na produção do podcast é relevante, pois, na } \\
\text { prática, com o preparo você se solta e ainda aprende o assunto"; }\end{array}$ \\
\hline $\begin{array}{l}\text { Aprendizagem } \\
\text { facilitada }\end{array}$ & $\begin{array}{l}\text { "Ao ouvir entende-se o assunto de maneira mais fácil, pois é como um } \\
\text { professor explicando"; }\end{array}$ \\
\hline Acessibilidade & "Pode ser utilizado com alunos cegos"; \\
\hline Aprofundamento & $\begin{array}{l}\text { "Desenvolve a criatividade, a capacidade de falar ao público, auxilia no } \\
\text { aprofundamento dos estudos para selecionar o conteúdo do podcast, } \\
\text { entre outros." }\end{array}$ \\
\hline
\end{tabular}

Fonte: Autores (2020). 
Notamos que as possíveis vantagens do uso de podcast-edu foram significativamente reconhecidas e ressaltadas pelas estudantes respondentes. Esses aspectos dialogam com diversos apontamentos encontrados na literatura sobre o tema. Vale destacar que, além dos apontamentos das vantagens destacadas pelas estudantes, foram identificadas outras vantagens a serem exploradas com a prática, tais como a melhora da oralidade e da escrita, o compartilhamento de conteúdo entre os(as) estudantes e a construção da autoestima do corpo discente. Se considerarmos que o principal instrumento do professor é sua voz, produzir podcasts durante o processo de formação de professores é uma atividade que pode aperfeiçoar a oralidade, incluindo aqui a entonação da voz, a dicção e a dinâmica dos usos das palavras e frases, como apresentou Sampaio-Silva (2019).

Notamos que houve o reconhecimento de que o podcast potencializa a autonomia discente, levando-os a descobrir fontes de pesquisas e a tomar decisões quanto a seleção das informações encontradas. Silva (2017) também notou que os professores em formação, que participaram do curso de podcast, também destacaram o caráter potencializador da autonomia discente.

Também buscamos identificar a percepção das estudantes quanto as desvantagens do uso do podcast em sala de aula. As respostas obtidas são sintetizadas e apresentadas no quadro 5:

Quadro 5: Perspectivas das estudantes quanto aos possíveis aspectos negativos do uso de podcasts na Educação.

\begin{tabular}{|l|l|}
\hline \multicolumn{1}{|c|}{ Aspecto ressaltado } & \multicolumn{1}{c|}{ Síntese dos relatos } \\
\hline Limites tecnológicos & Ausência de recurso visual \\
\hline Monótono & $\begin{array}{l}\text { Dependendo do assunto e de como é feito pode se tornar } \\
\text { cansativo de ouvir e monótono; }\end{array}$ \\
\hline Dificuldade na produção & Alguns alunos não saberiam produzir; \\
\hline Carência de interatividade & Ao ouvir podcasts não é possível tirar dúvidas; \\
\hline $\begin{array}{l}\text { Não identificação com o } \\
\text { recurso }\end{array}$ & O aluno pode não se identificar com a didática; \\
\hline $\begin{array}{l}\text { Dificuldade na produção } \\
\text { O aluno pode sentir tensão e vergonha em ter que produzir um } \\
\text { podcast. }\end{array}$ \\
\hline
\end{tabular}

Fonte: Autores (2020). 
Os apontamentos das estudantes trazidos como desvantagens existentes no uso de podcasts na educação são pertinentes e nos permitem esclarecer dois pontos: i) enquanto uma ferramenta que pode favorecer o ensino e a aprendizagem dos conteúdos, o podcast não deve ser o único instrumento utilizado em sala de aula, mas deve ser somado a outras alternativas, oferecendo equilíbrio de atividades, uma vez que alguns podem se identificar com o recurso didático e outros não; ii) outro esclarecimento refere-se a tensão e/ou vergonha que eventualmente pode vir a ser ocasionada a alguns dos(as) estudantes ao ter que produzir áudios, sendo que para esses casos pode ser recomendável que sejam direcionados à participar da produção dos roteiros, da pesquisa dos conteúdos e assuntos a serem discutidos no episódio, da edição das gravações e do formato do programa. Importa criar meios promotores de condições de desenvolvimento de variadas habilidades e competências e a produção de podcasts é promissora para isso. Segundo Souza (2006, p. 71-72):

[O] professor pode envolver os alunos em diferentes áreas do processo de gravação do podcast. Alguns alunos podem gerir os equipamentos de gravação, outros podem editar enquanto alguns cuidam, por exemplo, da divulgação do feed do podcast.

Em síntese, pelo exposto por meio de um breve estado da arte, de experiências relatadas em periódicos científicos e nosso experimento com futuras professoras, podemos inferir que muitas são as possibilidades de trabalhar com o podcast em sala de aula de modo a favorecer a aprendizagem dos conteúdos e colaborar com a formação de futuros professores. Nosso experimento, à despeito da limitação do público envolvido, revelou que as estudantes tiveram a aprendizagem potencializada e mostram-se favoráveis ao uso dessa tecnologia para o estudo e socialização dos conteúdos acadêmicos, evidenciando que tal ferramenta deve ter seu uso considerado pelos docentes no conjunto dos recursos didáticos viáveis e colaborativos ao ensino-aprendizagem, bem como se apresenta como prática colaborativa à formação de professores. 


\section{Conclusão}

Neste artigo discutimos as potencialidades dos usos de podcast como estratégia de ensino-aprendizagem, com foco na formação de professores. Ao observarmos a produção científica sobre podcast-edu voltados as referidas disciplinas identificamos a escassez de publicações e a descontinuidade das pesquisas por parte dos que defenderam dissertações e teses sobre o tema, o que não significa que não se utilizem do recurso em suas práticas. Ainda que o volume de pesquisas seja reduzido, os apontamentos de suas possibilidades didático-pedagógicas na educação formal é significativamente numerosa, o que evidencia ser um recurso que merece atenção dos docentes no momento de suas escolhas didáticas. Nossa percepção, a partir do experimento de pesquisa-ação realizado em uma turma do curso de Pedagogia, nos deixou otimista quanto aos usos de podcasts em sala de aula, sobretudo por ter potencializado a aprendizagem do conteúdo em estudo. A percepção das professoras em formação quanto aos benefícios do uso de podcasts também foi positiva.

Dentre as potencialidades do podcast-edu destacamos: a possibilidade de promover processo de ensino-aprendizagem significativo e satisfatório; permitir que espaços públicos sejam espaços de ensino; possibilitar a interconexão entre o espaço escolar e o ciberespaço, o que amplia a divulgação do conhecimento; propiciar o desenvolvimento de diversas outras habilidades e competências para além do daquelas diretamente relacionadas ao conteúdo estudado; poder vir a ser estratégia de redução da timidez do corpo discente; ser uma oportunidade destes aprenderem a trabalhar de forma colaborativa; ser meio de valorização dos conhecimentos que o corpo discente já possuía; abrir espaço para diferentes formas de se construir o pensamento; proporcionar satisfação e orgulho dos(as) estudantes em relação às suas produções e; tornar os(as) estudantes como agentes produtores de conhecimento. É certo que as 
limitações dos usos de podcasts também precisam ser consideradas pelos docentes ao tomá-los como recursos didáticos.

O experimento, associado à análise da percepção dos professores em formação participantes, nos permitiu observar, ao menos no caso em pauta, que o uso de podcasts educativos em turmas de Pedagogia não só potencializa a aprendizagem dos(as) estudantes, como também lhes apresenta possibilidades de usos desse recurso didático que comporá seu repertório, o qual poderão mobilizar quando estiverem lecionando. Podemos inferir que as possibilidades múltiplas do uso de podcast já indicadas pela reduzida literatura revelam ser um objeto de pesquisa que precisa ser privilegiado, assim como a necessidade de que outras experiências docentes sejam publicizadas e analisadas para que possamos compreender melhor as potencialidades e limitações que pelos limites desta pesquisa não foram desveladas. Nos parece que o uso de tecnologia na educação tem tornado ainda mais evidente a necessidade de problematizarmos os usos de ferramentas educacionais como o podcast$e d u$ a fim de que suas pontencializades - como recurso didático - sejam exploradas ao máximo em prol da qualificação do processo de ensinoaprendizagem, seja em contextos de EaD ou no ensino presencial.

\section{Referências}

BARROS, G.; MENTA, E. Podcast: produções de áudio para educação de forma crítica, criativa e cidadã. Sergipe. Revista de Economía Política de las Tecnologías de la Información y Comunicación, São Cristóvão, v. 9 $\mathrm{n}^{\mathrm{o}} .1$, p.1-14, abr. 2007.

CAPES. Coordenação de Aperfeiçoamento de Pessoal de Nível Superior. Mestrado Profissional: o que é?. Brasília, abril, 2014.

KISCHINHEVSKY, M. Manguebit e novas estratégias de difusão diante da reestruturação da indústria fonográfica. Rio de Janeiro. C.legenda, n. 16, p. 1-12, 2006. 
LOURES, J. V. Podcasts de Storytelling: A produção de narrativas históricas digitais para o ensino de História. 2018. 99 f. Dissertação (mestrado em Ensino de História) - Universidade Federal de Santa Catarina. Florianópolis, Santa Catarina, 2018.

PAIXÃO, Y. N. da F. O uso da narrativa transmídia no ensino de Geografia. 2016. 225 f. Tese. (doutorado em Geografia) - Universidade do Estado do Rio de Janeiro. Rio de Janeiro/RJ, 2016.

PRIMO, A. Para além da emissão sonora: as interações no podcasting. Porto Alegre Intexto, n. 13, p. 1-23, jul./dez. 2005.

SAMPAIO-SILVA, R.; BODART, C. das N. O uso do Podcast como recurso didático de Sociologia: aproximando habitus. Educação, Ciência e Cultura, Canoas, v. 20, n.1, p. 137-153, jan./jun. 2015. DOI:

https://doi.org/10.18316/2236-6377.15.9.

SAMPAIO-SILVA, R. O uso de recursos sonoros em aulas de sociologia para o Ensino Médio. In: BODART, C. das N.; SAMPAIO-SILVA, R. (Orgs.) O ensino de Sociologia no Brasil, vol.2. Maceió: Editora Café com Sociologia, 2019. pp. 77-98.

SILVA, A. G. A. da. O que são artefatos culturais, materiais pedagógicos e recursos didáticos? Blog Café com Sociologia, Maceió, mai. 2020.

SILVA, W. K. O uso pedagógico do podcast e formação inicial do professor: mudanças de paradigma educacional. 2017. 99. f. Dissertação (mestrado em Educação) - Universidade Estadual do Centro-Oeste, Guarapuava, 2017.

SOUZA, R. F. de. Usos e possibilidades do podcast no ensino de História. 2016. 106 f. Dissertação (mestrado em Ensino de História) - Universidade Federal do Rio de Janeiro, 2016.

SOUZA, R. F. O podcast no ensino de História e as demandas do tempo presente: que possibilidades? Rio de Janeiro. Transversos: Revista de História, Rio de Janeiro, n. 11, p. 42-62, dez. 2017. DOI: https://doi.org/10.12957/transversos.2017.31585. 